General Research

\title{
AQUEOUS TWO-PHASE SYSTEMS: A CORRELATION ANALYSIS
}

\author{
Marlen Gonzalez-Amado, Oscar Rodriguez, Ana Soto, Paloma
}

Carbonell Hermida, Maria del Mar Olaya, and Antonio Marcilla

Ind. Eng. Chem. Res., Just Accepted Manuscript • DOI: 10.1021/acs.iecr.9b06078 • Publication Date (Web): 26 Feb 2020

Downloaded from pubs.acs.org on March 2, 2020

\section{Just Accepted}

"Just Accepted" manuscripts have been peer-reviewed and accepted for publication. They are posted online prior to technical editing, formatting for publication and author proofing. The American Chemical Society provides "Just Accepted" as a service to the research community to expedite the dissemination of scientific material as soon as possible after acceptance. "Just Accepted" manuscripts appear in full in PDF format accompanied by an HTML abstract. "Just Accepted" manuscripts have been fully peer reviewed, but should not be considered the official version of record. They are citable by the Digital Object Identifier (DOI@). "Just Accepted" is an optional service offered to authors. Therefore, the "Just Accepted" Web site may not include all articles that will be published in the journal. After a manuscript is technically edited and formatted, it will be removed from the "Just Accepted" Web site and published as an ASAP article. Note that technical editing may introduce minor changes to the manuscript text and/or graphics which could affect content, and all legal disclaimers and ethical guidelines that apply to the journal pertain. ACS cannot be held responsible for errors or consequences arising from the use of information contained in these "Just Accepted" manuscripts. 


\title{
AQUEOUS TWO-PHASE SYSTEMS: A CORRELATION ANALYSIS
}

\author{
Marlén González-Amado ${ }^{1}$, Oscar Rodríguez ${ }^{1}$, Ana Soto ${ }^{1}$, Paloma Carbonell-Hermida ${ }^{3}$, \\ María del Mar Olaya ${ }^{2,3}$, Antonio Marcilla ${ }^{2,3^{*}}$ \\ ${ }^{1}$ Cretus Institute. Department of Chemical Engineering, Universidade de Santiago de \\ Compostela, E-15782, Santiago de Compostela, Spain \\ 2 Department of Chemical Engineering, University of Alicante, Apdo. 99, 03080 \\ Alicante, Spain. \\ ${ }^{3}$ Institute of Chemical Process Engineering, University of Alicante, 03080, Alicante, \\ Spain
}

\begin{abstract}
Aqueous two-phase systems involve a limited region of a complicated phase diagram usually containing solid phases. Studies regarding these systems generally focus on the liquid-liquid region because it provides a suitable medium for liquid extraction of biomolecules and metal ions. In this work, the whole phase diagram was determined for ternary mixtures of water, dipotassium tartrate and ethanol or propanol at several temperatures and atmospheric pressure. In addition, density and refractive index of a diluted region of the mixtures were measured for compositional analysis of samples. Different regions were found involving solid and liquid phases, or the anhydrous and hemi-hydrated salt. The correlation of equilibrium data within the different regions was carried out with the NRTL model. To that aim, some restrictions were required to ensure the miscibility of the binary subsystem with water and alcohol. Individual correlation at each temperature and simultaneous correlation of data at all temperatures led to adequate phase diagram representation and low deviations. In spite of the use of temperature dependent parameters, results were slightly worse in the latter case (around or below 1\%). The LLE data alone were also correlated, obtaining similar deviations to those obtained considering all equilibrium data. In all cases deviations found with propanol are higher (in the range of 3-4\%) due to the proximity of the LLE region to the miscible water + propanol binary subsystem. The correlation of exclusively LLE data is
\end{abstract}

${ }^{*}$ Corresponding author. E-mail address: Antonio.M arcilla@ua.es 
easier from the point of view of computation but leads to model parameters with limited utility.

\section{Introduction}

Aqueous two-phase systems (ATPS) are promising for the separation of biomolecules keeping their nature unaltered. Nonetheless, their applications go far beyond bioseparations and ATPS have been proposed for many different processes such as metal separations, bio-printing, microencapsulation, etc. ${ }^{1}$ Traditionally, two polymers or a polymer and a salt have been used as phase-forming agents to generate immiscible aqueous phases in equilibrium. ${ }^{2}$ But nowadays a large variety of chemicals have been proposed as phase-forming agents, including small organic molecules, sugars, surfactants, ionic liquids, etc. ${ }^{3-7}$ A point of discussion about these new components used for ATPS formulation could be the occasionally rather low proportion of water in the equilibrium phases.

As their name indicates, the interest of ATPS lies in the range of concentrations and conditions where a low quantity of chemicals leads to two aqueous phases in equilibrium. Phase diagrams are usually considered ternary (water and two phaseforming components) and determined in a partial region of interest for the application. Thus, the experimental equilibrium data are frequently measured and correlated exclusively in the liquid-liquid equilibrium (LLE) area, and most times for a limited concentration range not covering the whole LLE region. Moreover, data treatment is frequently limited to the application of empirical or semi-empirical models, such as Merchuk or Guan and co-workers equations. ${ }^{8,9}$ When activity coefficient models are used, data on solid-liquid equilibrium regions are generally not considered.

When a salt is one of the phase-forming components, the global phase equilibrium behaviour of the system includes the presence of solid, either anhydrous (S) or hydrated (Sh), in equilibrium with liquid phases. Figure 1 shows a general representation for a water + alcohol + salt ATPS where all possible equilibrium regions are considered. The widespread practice of determining and correlating data only in the LLE region provides a partial knowledge of the phase behaviour of the system, and the set of model parameters obtained using these data has a limited utility. So, if these model parameters are included in conventional software for chemical process simulations, the 
extrapolation out of the margins where these parameters have been obtained might provide erroneous phase equilibrium calculations.

In order to obtain useful parameters for any equilibrium calculation, not only for the ternary LLE region, a more rigorous correlation is required. The simultaneous correlation (with a unique set of parameters) of phase equilibrium data homogeneously distributed in all the equilibrium regions of the system (at the temperature and pressure established) is required. This means that the parameters must satisfy the equilibrium conditions not only in the LLE region, but also in all the existing Liquid-Solid (LS) and Liquid-Liquid-Solid (LLS) equilibrium regions, including the possible presence of anhydrous (S) and hydrated salt (Sh): LShE, LLShE, LSShE, etc.

In the present paper, the equilibrium data for water + ethanol or propanol + dipotassium tartrate systems are measured at different temperatures (288.15, 298.15 and 308.15 K) using physical properties (density and refractive index) of the ternary mixtures for compositional analysis of the equilibrium phases. These systems are used as a case study to analyse the advantages and drawbacks of carrying out a partial correlation (only LLE data) versus the complete correlation considering all the different phase equilibria regions involved. The Non-Random Two-Liquid (NRTL) model ${ }^{10}$, known for its versatility, was selected to that aim. Future works should consider the use of more advanced models such as ePC-SAFT or eCOSMO-RS that have been already showed useful in the modelling of the effect of salt on LLE. ${ }^{11,12}$

\section{Procedure}

\section{Materials}

Ethanol $\left(\mathrm{C}_{2} \mathrm{H}_{5} \mathrm{OH},>99.8 \%\right.$, for analysis $)$ and 1-Propanol $\left(\mathrm{C}_{3} \mathrm{H}_{7} \mathrm{OH},>99.9 \%\right.$, Chromasol) were obtained from Panreac Applichem and Riedel-de Haën, respectively. Potassium tartrate dibasic hemihydrate $\left(\mathrm{C}_{4} \mathrm{H}_{4} \mathrm{~K}_{2} \mathrm{O}_{6} \cdot 0.5 \mathrm{H}_{2} \mathrm{O}\right.$, >99\%) was purchased from Sigma. The salt was dried at $40{ }^{\circ} \mathrm{C}$ for at least $24 \mathrm{~h}$ to eliminate adsorbed water and used without further purification. Molecular sieves $(0.3 \mathrm{~nm}$ from Merck) were used with alcohols to remove all traces of moisture prior to their use. Distilled water was used for ATPS formulation and sample dilutions. The CAS number, supplier and purity of the chemicals used in this work are presented in Table 1. 


\section{Experimental methods}

Initially, calibration curves were prepared at $298.15 \mathrm{~K}$ and atmospheric pressure for compositional analysis of samples. Density (determined with a densimeter Anton Paar DSA 48) was used to obtain the composition of the binary mixtures, and this property and refractive index (determined with an Atago RX 5000) were used in the case of the ternary mixtures. Compositions were always corrected taking into account the water content of the hydrated salt, in order to have the physical properties as a function of the concentration of the anhydrous salt. All weighting was carried out on a Mettler Toledo balance model XPE205. Physical properties and correlation are presented in Supporting Information (Tables S1 to S4).

To determine LLE data for the ternary systems, suitable amounts of salt, alcohol and water were added to the equilibrium cell to obtain mixtures within the corresponding region. A thermostatic bath Julabo F12-EH was used to maintain constant working temperatures $(288.15,298.15$ or $308.15 \mathrm{~K})$. The system was agitated 30 min using a magnetic stirrer, and then allowed to settle during $24 \mathrm{~h}$ until the two equilibrium phases were completely clear and separated. Preliminary tests showed that times for agitation and sedimentation were sufficient to attain equilibrium and achieve a good separation of the phases. Then, samples from the top and bottom phases were withdrawn and diluted appropriately for compositional analysis using density and refractive index calibration curves. Samples of each equilibrium phase were measured in duplicate, ensuring that the compositions obtained from density and refractive index measurements were replicated within the expected uncertainty.

To determine the LLShE tie-triangle, water and alcohol were added in appropriate amounts to lie within the corresponding region whereas the salt was added in excess to overcome the salt solubility limit. Following the procedure described above, liquid phase composition was determined through the measurement of the physical properties. A sample of the solid phase was also removed from the cell and dried in an oven $(323.15 \mathrm{~K})$ until its weight was stable. Then, the solid sample was dissolved in a known amount of distilled water and its composition determined from the density measurement. The same procedure was used to determine equilibrium compositions of mixtures lying in the LSh region. The solubility of the hydrated salt in water was determined in a previous publication ${ }^{13}$. To determine the solubility of the anhydrous salt in alcohol, the dehydration temperature for potassium tartrate was measured 
experimentally by Thermal Gravimetric Analysis using a TA Instruments model Q500. A temperature ramp of $5 \mathrm{~K} / \mathrm{min}$ was used from ambient to $523 \mathrm{~K}$. Dehydration started at $423 \mathrm{~K}$ and decomposition of the salt started at about $513 \mathrm{~K}$. Then, a sample of the hemihydrate salt was oven dried at $448 \mathrm{~K}$ until weight remained constant, and dehydration was confirmed by TGA. Finally, the SLE was determined experimentally and the liquid composition was carried out by means of ion chromatography (Metrohm 861 Advanced Compact IC with a column Metrosep C3 250/4.0 mm). The absence of water in the solid phase was corroborated by TGA.

\section{Data treatment}

For the correlation of the equilibrium data, the Gibbs common tangent equilibrium condition was applied considering the possible existence of liquid and solid phases. Such procedure simultaneously solves orthogonal derivatives, the tangent plane equations and the mass balances, as already explained in a previous paper. ${ }^{14}$

In the LL region, a ternary mixture with two liquid phases $\alpha$ and $\beta$ in equilibrium (tieline) is defined by the common tangent plane equation:

$$
F_{1} \equiv\left(g^{\beta}-g^{\alpha}\right)-\left(x_{1}^{\beta}-x_{1}^{\alpha}\right)\left(\frac{\partial g}{\partial x_{1}}\right)_{T, P, x_{2}}^{\alpha \text { or } \beta}-\left(x_{2}^{\beta}-x_{2}^{\alpha}\right)\left(\frac{\partial g}{\partial x_{2}}\right)_{T, P, x_{1}}^{\alpha \text { or } \beta}=0
$$

where $g$ stands for the molar Gibbs energy $(g=G / R T)$, and $x_{1}$ and $x_{2}$ are mole fractions of components 1 and 2. The following conditions must be fulfilled,

$$
\begin{aligned}
& \mathrm{F}_{2} \equiv\left(\frac{\partial \mathrm{g}}{\partial \mathrm{x}_{1}}\right)_{\mathrm{T}, \mathrm{P}, \mathrm{x}_{2}}^{\alpha}-\left(\frac{\partial \mathrm{g}}{\partial \mathrm{x}_{1}}\right)_{\mathrm{T}, \mathrm{P}, \mathrm{x}_{2}}^{\beta}=0 \\
& \mathrm{~F}_{3} \equiv\left(\frac{\partial \mathrm{g}}{\partial \mathrm{x}_{2}}\right)_{\mathrm{T}, \mathrm{P}, \mathrm{x}_{1}}^{\alpha}-\left(\frac{\partial \mathrm{g}}{\partial \mathrm{x}_{2}}\right)_{\mathrm{T}, \mathrm{P}, \mathrm{x}_{1}}^{\beta}=0
\end{aligned}
$$

In LS and LSh regions, a ternary mixture of one liquid phase $(\alpha)$ in equilibrium with one solid is defined by a tangent plane to the $g$ surface at the liquid equilibrium composition $x_{i}^{\alpha}$, that also includes the $g$ value for the solid $g^{*}\left(g^{S}\right.$ or $\left.g^{S h}\right)$ : 


$$
\mathrm{F}_{4} \equiv\left(\mathrm{g}^{*}-\mathrm{g}^{\alpha}\right)-\left(\mathrm{x}_{1}^{*}-\mathrm{x}_{1}^{\alpha}\right)\left(\frac{\partial \mathrm{g}}{\partial \mathrm{x}_{1}}\right)_{\mathrm{T}, \mathrm{P}, \mathrm{x}_{2}}^{\alpha}-\left(\mathrm{x}_{2}^{*}-\mathrm{x}_{2}^{\alpha}\right)\left(\frac{\partial \mathrm{g}}{\partial \mathrm{x}_{2}}\right)_{\mathrm{T}, \mathrm{P}, \mathrm{x}_{1}}^{\alpha}=0
$$

In the LLSh region, the tangent plane to the $g$ surface at the two liquid phases ( $\alpha$ and $\beta$ ) that also contains the point corresponding to the hydrated solid $\left(g^{S h}\right)$ is given by:

$$
\begin{aligned}
& \mathrm{F}_{5} \equiv\left(\mathrm{g}^{\beta}-\mathrm{g}^{\alpha}\right)-\left(\mathrm{x}_{1}^{\beta}-\mathrm{x}_{1}^{\alpha}\right)\left(\frac{\partial \mathrm{g}}{\partial \mathrm{x}_{1}}\right)_{\mathrm{T}, \mathrm{P}, \mathrm{x}_{2}}^{\alpha \text { or } \beta}-\left(\mathrm{x}_{2}^{\beta}-\mathrm{x}_{2}^{\alpha}\right)\left(\frac{\partial \mathrm{g}}{\partial \mathrm{x}_{2}}\right)_{\mathrm{T}, \mathrm{P}, \mathrm{x}_{1}}^{\alpha \text { or } \beta}=0 \\
& \mathrm{~F}_{6} \equiv\left(\mathrm{g}^{\mathrm{Sh}}-\mathrm{g}^{\alpha}\right)-\left(\mathrm{x}_{1}^{\mathrm{Sh}}-\mathrm{x}_{1}^{\alpha}\right)\left(\frac{\partial \mathrm{g}}{\partial \mathrm{x}_{1}}\right)_{\mathrm{T}, \mathrm{P}, \mathrm{x}_{2}}^{\alpha \text { or } \beta}-\left(\mathrm{x}_{2}^{\mathrm{Sh}}-\mathrm{x}_{2}^{\alpha}\right)\left(\frac{\partial \mathrm{g}}{\partial \mathrm{x}_{2}}\right)_{\mathrm{T}, \mathrm{P}, \mathrm{x}_{1}}^{\alpha \text { or } \beta}=0 \\
& \mathrm{~F}_{7} \equiv\left(\frac{\partial \mathrm{g}}{\partial \mathrm{x}_{1}}\right)_{\mathrm{T}, \mathrm{P}, \mathrm{x}_{2}}^{\alpha}-\left(\frac{\partial \mathrm{g}}{\partial \mathrm{x}_{1}}\right)_{\mathrm{T}, \mathrm{P}, \mathrm{x}_{2}}^{\beta}=0 \\
& \mathrm{~F}_{8} \equiv\left(\frac{\partial \mathrm{g}}{\partial \mathrm{x}_{2}}\right)_{\mathrm{T}, \mathrm{P}, \mathrm{x}_{1}}^{\alpha}-\left(\frac{\partial \mathrm{g}}{\partial \mathrm{x}_{2}}\right)_{\mathrm{T}, \mathrm{P}, \mathrm{x}_{1}}^{\beta}=0
\end{aligned}
$$

Finally, in the LSSh region, the plane containing $g^{S}$ and $g^{S h}$ and tangent to the $g$ surface at the liquid phase molar fraction $\left(x_{i}^{\alpha}\right)$ is defined by:

$$
\begin{aligned}
& \mathrm{F}_{9} \equiv\left(\mathrm{g}^{\mathrm{S}}-\mathrm{g}^{\alpha}\right)-\left(\mathrm{x}_{1}^{\mathrm{S}}-\mathrm{x}_{1}^{\alpha}\right)\left(\frac{\partial \mathrm{g}}{\partial \mathrm{x}_{1}}\right)_{\mathrm{T}, \mathrm{P}, \mathrm{x}_{2}}^{\alpha}-\left(\mathrm{x}_{2}^{\mathrm{S}}-\mathrm{x}_{2}^{\alpha}\right)\left(\frac{\partial \mathrm{g}}{\partial \mathrm{x}_{2}}\right)_{\mathrm{T}, \mathrm{P}, \mathrm{x}_{1}}^{\alpha}=0 \\
& \mathrm{~F}_{10} \equiv\left(\mathrm{g}^{\mathrm{Sh}}-\mathrm{g}^{\alpha}\right)-\left(\mathrm{x}_{1}^{\mathrm{Sh}}-\mathrm{x}_{1}^{\alpha}\right)\left(\frac{\partial \mathrm{g}}{\partial \mathrm{x}_{1}}\right)_{\mathrm{T}, \mathrm{P}, \mathrm{x}_{2}}^{\alpha}-\left(\mathrm{x}_{2}^{\mathrm{Sh}}-\mathrm{x}_{2}^{\alpha}\right)\left(\frac{\partial \mathrm{g}}{\partial \mathrm{x}_{2}}\right)_{\mathrm{T}, \mathrm{P}, \mathrm{x}_{1}}^{\alpha}=0
\end{aligned}
$$

The NRTL model was used for data correlation. In a previous paper ${ }^{15}$ we found that the use of the eNRTL model did not improve many of results obtained using NRTL in LLE correlations in presence of salts. For this reason, we have chosen a very extended and simple model, like the NRTL, to correlate phase diagrams of both ternary systems (considering all the regions involved) at 288.15, 298.15 and $308.15 \mathrm{~K}$. In all the cases, the non-randomness parameter $\alpha_{i j}$ has been optimised during the correlation because using constant values of 0.2 or 0.3 as recommended in some cases for simpler systems, yield very poor correlation results. 
In order to carry out a simultaneous correlation at all the temperatures for each ternary system, the dependence of the NRTL correlation parameters with temperature was considered according to the following equation:

$\tau_{\mathrm{ij}}=\mathrm{a}_{\mathrm{ij}}+\frac{\mathrm{b}_{\mathrm{ij}}}{\mathrm{T}}+\mathrm{c}_{\mathrm{ij}} \cdot \ln \mathrm{T}+\mathrm{d}_{\mathrm{ij}} \cdot \mathrm{T}$

where $\mathrm{a}_{i j}, b_{i j}, c_{i j}$, and $d_{i j}$ are the parameters of the model and $T$ is the temperature $(\mathrm{K})$.

In order to compare results, LLE data (just this region) of the ternary systems at each work temperature were also correlated.

The optimisation of the NRTL parameters was carried out using the GRG (Generalized Reduced Gradient) method to minimise the objective function defined in Eq. (12) along with the fulfilment of all the equilibrium conditions given from Eq. (1) to (10).

$$
\operatorname{O.F}(\mathrm{x})=\min \sum_{\mathrm{n}=1}^{\mathrm{nd}} \sum_{\mathrm{i}=1}^{3}\left[\left(\mathrm{x}_{\mathrm{i}, \mathrm{n}}\right)_{\exp }-\left(\mathrm{x}_{\mathrm{i}, \mathrm{n}}\right)_{\text {cal }}\right]^{2} \quad \text { subject to } \quad \sum_{j=1}^{10}\left(\mathrm{~F}_{\mathrm{j}}\right)^{2}<\varepsilon
$$

This objective function includes the comparison between experimental (exp) and calculated (cal) mole fractions $\left(x_{i}\right)$ for all the $i$-components in the liquid phases in equilibrium both with other liquid or solid phases. nd is the total number of liquid equilibrium data and $\varepsilon$ is an extremely low tolerance value guaranteeing the fulfilment of the equilibrium conditions based on the Gibbs tangent plane criterion $\left(\varepsilon<10^{-9}\right.$ in this work).

A significant problem in the correlation of this kind of systems usually appears when no restriction is included during the fitting process, which is the common practice. The 1-2 binary subsystem (see Figure 1) easily tends to split in LLE, providing an inconsistent result. This is because of the proximity of the experimental LLE ternary region to this binary subsystem (water + alcohol in this case). This issue has previously been studied. ${ }^{16-19}$ So, in order to guarantee the miscibility of the binary water + alcohol subsystem, new restrictions must be defined. In a previous work ${ }^{17}$, the boundary definition $\tau_{\mathrm{ji}}=\mathrm{f}\left(\tau_{\mathrm{ij}}\right)$ between miscible (L) and partially miscible (LLE) regions was presented for the NRTL dimensionless parameters $\left(\tau_{i j}\right.$ and $\left.\tau_{j i}\right)$ and $\alpha_{i j}=0.2$. This boundary definition $\tau_{\mathrm{ji}}=\mathrm{f}\left(\tau_{\mathrm{ij}}\right)$ is given by the following equations:

$\tau_{\mathrm{ij}}<-3 \quad \tau_{\mathrm{ji}}^{\mathrm{F}}=-1.833 \cdot \tau_{\mathrm{ij}}+1.423$ 


$$
\begin{array}{ll}
-3<\tau_{\mathrm{ij}}<7 & \tau_{\mathrm{ji}}{ }^{\mathrm{F}}=-4.191 \cdot 10^{-3} \cdot \tau_{\mathrm{ij}}{ }^{3}+9.089 \cdot 10^{-2} \cdot \tau_{\mathrm{ij}}{ }^{2}-1.206 \cdot \tau_{\mathrm{ij}}+2.481 \\
\tau_{\mathrm{ij}}>7 & \tau_{\mathrm{ji}}{ }^{\mathrm{F}}=-0.545 \cdot \tau_{\mathrm{ij}}+0.7758
\end{array}
$$

The $i$-j pair is totally miscible for $\tau_{j i}<\tau_{j i}^{F}$ and splits in LLE for $\tau_{j i}>\tau_{j i}{ }^{F}$. The above restrictions depend on the non-randomness parameter $\left(\alpha_{i j}\right)$. However, the representation of $\tau_{j i}$ versus $\tau_{i j}$ for different values of $\alpha_{i j}$ showed that the variation of the frontier is not very significant. The correlation results presented in this paper have been obtained using this type of restrictions and consequently they obey to the real behaviour of miscibility of the water + alcohol binary subsystem.

\section{Results}

\subsection{Phase diagrams}

Tables 2 and 3 present the experimental equilibrium data for water + ethanol + dipotassium tartrate and water + propanol + dipotassium tartrate, respectively, ternary systems at 288.15, 298.15 and $308.15 \mathrm{~K}$ and atmospheric pressure. Figures 2 and 3 show the corresponding phase diagrams at $288.15 \mathrm{~K}$. The region of interest from the point of view of application of the ATPS is the LLE region. However, an effort has been also carried out to determine tie-lines corresponding to the LS and LSh regions, and LLSh tie-triangle (see Figure 1).

As it is well-known, the binary subsystem water + alcohol is miscible at all temperatures. The solubility obtained for the anhydrous salt in the alcohols (ethanol or propanol) was very low ( $<100 \mathrm{ppm}$, by ion chromatography). Similarly, when equilibrium data were obtained in the LSh region close to the LSSh tie-triangle (see Figure 1), the liquid phase obtained was alcohol with very low water and salt content. Indeed, the liquid phase in this LSSh tie-triangle was almost pure alcohol within the uncertainty of our experimental technique based on physical properties. For that reason, the LS region for the studied systems is extremely small. On the other hand, the LLSh tie-triangle is very close to the water + salt subsystem, so the corresponding LSh region is also extremely small. These facts explain why in Tables 2 and 3 the LSh and LS regions are defined exclusively by one tie-line corresponding to each binary.

Focusing on ATPS applications, the LLE region increases with alcohol chain length. This behaviour was also found by other authors for systems containing these alcohols 
and inorganic salts. ${ }^{20-22}$ The reason has been attributed to the difference in alcohol/water and alcohol/alcohol interactions as the alcohol alkyl chain increases (specifically the increase in van der Waals interactions due to the larger alkyl chain ${ }^{20}$ ). The effect of the type of salt is more difficult to discuss since both anion and cation will affect the phase diagram. In general, higher charge density provides greater ability for ATPS formation (sodium cation more effective than potassium) and higher ion valence also increases the ability of the ion for ATPS formation, according to our results and those from literature. ${ }^{20-22}$ Temperature also increases the tie-line length (size of the LLE region). Both alcohol chain length and temperature increase the alcohol content in the top phase. It is important to highlight that this increase in alcohol content in the top phase can drastically reduce the "aqueous" nature of the ATPS for some alcohol chain lengths and temperatures (here, 1-propanol). Comparison with available data is possible for the water + 1-propanol + potassium tartrate ATPS at $298.15 \mathrm{~K}^{23}$ Our results are in good agreement, with slightly higher salt composition in the alcohol-rich phase, but length and slope of the tie-lines are similar.

\subsection{Correlation}

Data treatment requires $g^{S}$ and $g^{S h}$ for the anhydrous and hydrated solid salt, respectively. These values can be obtained as the chemical potential change from the pure liquid (reference state) to the pure solid salt at $\mathrm{T}$ and $\mathrm{P}$ conditions, using a thermodynamic cycle ${ }^{24}$ :

$$
\mathrm{g}^{\mathrm{s}^{*}}=\frac{\Delta \mu^{\mathrm{s}}}{\mathrm{RT}}=\frac{\Delta \mathrm{h}_{\mathrm{f}}}{\mathrm{RT}_{\mathrm{f}}}\left(1-\frac{\mathrm{T}_{\mathrm{f}}}{\mathrm{T}}\right)+\frac{1}{\mathrm{RT}} \int_{\mathrm{T}}^{\mathrm{T}_{\mathrm{f}}} \Delta \mathrm{C}_{\mathrm{p}} \mathrm{dT}-\frac{1}{\mathrm{R}} \int_{\mathrm{T}}^{\mathrm{T}_{\mathrm{f}}} \frac{\Delta \mathrm{C}_{\mathrm{p}}}{\mathrm{T}} \mathrm{dT}
$$

where $\mu^{S}$ is the chemical potential for the solid, $\Delta h_{f}$ is the enthalpy of fusion at the normal melting temperature, $\Delta C_{p}$ is the difference between the liquid and solid heat capacities, and $T_{f}$ is the normal melting point. However, Eq. (14) requires some physical properties for both anhydrous and hemi-hydrate dipotassium tartrate that are not available in the literature or they are difficult, or even impossible, to measure due to decomposition of the salt. Considering this limitation, $g^{S}$ and $g^{S h}$ were also considered correlation parameters.

\section{Individual correlation}


Tables 4 and 5 present the binary interaction parameters obtained with the NRTL model for the correlation of all equilibrium data of ternary systems water + ethanol + dipotassium tartrate and water + propanol + dipotassium tartrate, respectively, at $288.15,298.15$ and $308.15 \mathrm{~K}$. These tables also include the Gibbs energy values for the anhydrous $\left(g^{S}\right)$ and hydrated $\left(g^{S h}\right)$ salt optimised during the correlation, along with the objective function values (Eq. 12) and the mean deviations between calculated and experimental mole fractions calculated by Eq. (15).

$$
\sigma(\%)=100 \times \sqrt{\frac{\sum_{\mathrm{n}=1}^{\mathrm{nd}} \sum_{\mathrm{i}=1}^{3}\left\{\left(\left(\mathrm{x}_{\mathrm{i}, \mathrm{n}}\right)_{\exp }-\left(\mathrm{x}_{\mathrm{i}, \mathrm{n}}\right)_{\mathrm{cal}}\right)_{\alpha}^{2}+\left(\left(\mathrm{x}_{\mathrm{i}, \mathrm{n}}\right)_{\exp }-\left(\mathrm{x}_{\mathrm{i}, \mathrm{n}}\right)_{\mathrm{cal}}\right)_{\beta}^{2}\right\}}{6 \cdot \mathrm{nd}}}
$$

Figures 2 and 3 show, for each ternary system, the comparison between experimental and calculated equilibrium data at $288.15 \mathrm{~K}$. Similar results have been obtained at the other temperatures. In Figures 4 and 5 rescaling has been carried out for a better visualisation of the LLE region at $288.15,298.15$ and $308.15 \mathrm{~K}$. It can be seen that the simultaneous fitting of all the equilibrium regions allows a good representation of the LLE region.

The mean deviations between experimental and calculated mole fractions are significantly higher with 1-propanol than those obtained for ethanol. These values are $3.23,3.72$ and $4.87 \%$ at $288.15,298.15$ and $308.15 \mathrm{~K}$, respectively, while they were less than 1 in all the cases for ethanol. The shape of the phase diagram for this system (Figure 3) would cause special difficulties to fit the data with any particular model. The reason is the proximity between the LLE ternary region and the totally miscible water + propanol binary subsystem.

In both cases, with ethanol or propanol, $g^{*}$ values increase with temperature, the values for the hydrated salt $\left(g^{S h}\right)$ being lower than those for the anhydrous one $\left(g^{S}\right)$.

\section{Simultaneous correlation}

A simultaneous correlation of all data-set for the ternary system water + ethanol + dipotassium tartrate was carried out. Results are shown in Table 6. An acceptable representation of all the equilibrium regions at all the temperatures was found with a unique set of parameters. The values of the mean deviations and the objective function are slightly higher than those obtained with the individual correlations in spite of using an elevated number of parameters. Contrarily to the case of individual correlation, the 
$g^{*}$ values found for the hydrated salt $\left(g^{S h}\right)$ are higher than those for the anhydrous one $\left(g^{S}\right)$, which is expected in order to better capture the effect of temperature.

Due to the problems found in the individual correlation of the ternary system water +1 propanol + dipotassium tartrate, the simultaneous correlation was not addressed since high deviations would be expected.

\section{Correlation of LLE data}

Most often, the interest in ATPS lies within the LLE region. Thus, a critical analysis of the advantages and drawbacks of the correlation of tie-lines uniquely in this region will be done. LLE data for the ternary system water + ethanol + dipotassium tartrate at 288.15, 298.15 and $308.15 \mathrm{~K}$, were correlated using the NRTL equation and results are shown in Supporting Information (Table S5). Mean deviations obtained are: 0.69, 0.52 and $0.79 \%$ at $288.15,298.15$ and $308.15 \mathrm{~K}$, respectively. These data can be compared with deviations obtained in the correlation of data from all the regions of the phase diagram: $0.63,0.52$ and $0.66 \%$. As can be seen, the most rigorous correlation gives very similar deviations. Similar results were obtained for the system with propanol (Table S6 in SI). The mean deviations obtained in this case are 3.35, 4.02 and 4.07\% at $288.15,298.15$ and $308.15 \mathrm{~K}$, respectively. These values are close to the deviations obtained from the correlation of all the equilibrium data: $3.23,3.72$ and $4.87 \%$, respectively. In this particular system it is evident that the limitations for the NRTL model to reproduce the equilibrium already exist for the fitting of the LLE data without considering the solids in equilibrium.

\section{Consistency of correlation}

The solutions obtained for all the correlations were checked to discard any possible metastable equilibrium solution ${ }^{16}$ and guarantee the consistency of the parameters for the whole composition range. $g^{M, L}$ surface for the liquid phase at each temperature, and also the $\mathrm{g}^{*}$ values for the anhydrous and hydrated solids were represented. From these figures, the validity of the correlation was checked through tangent planes in the calculated equilibrium compositions from all the regions, ensuring that they do not intersect the $g^{M, L}$ surface in any other composition, as required. As an example, Figure 6 shows this representation for the water + ethanol + dipotassium tartrate ternary system at $288.15 \mathrm{~K}$. A zoom and a rotation of the figure are also included for a better visualisation of the LLE region. Figure 7 shows the limits of this $3 \mathrm{D}$ figure, 
corresponding to the three binary subsystems: water + ethanol (7a), water + dipotassium tartrate (7b) and ethanol + dipotassium tartrate (7c). It can be seen that reported correlation parameters (Table 4) provide a $g^{M, L}$ curve that identifies the total miscibility of the water + ethanol binary subsystem. A tangent line connecting the liquid and solid phases in equilibrium can be seen in the other two binary subsystems. The 2-3 pair presents a $g^{M, L}$ curve with metastable LL splitting. Nonetheless, Figure 7c shows that the stable equilibrium solution is the liquid-solid equilibrium (tangent line to the $g^{M, L}$ curve including the $g^{S}$ point) because it leads to the lowest energy. Finally, some sectional planes from Figure 6 are presented in SI (Figure S1). From S1a to S1c, salt content decreases. It is interesting to see the common tangent line fulfilment and how LL region vanishes close to the water + ethanol binary subsystem.

\section{Conclusions}

The addition of dipotassium tartrate to a mixture of water + ethanol or water + propanol generates a phase diagram with very different regions: LL, LS, LSh, LLSh and LSSh being Sh the hemi-hydrate salt. Phase diagrams at atmospheric pressure and several temperatures were determined experimentally using density and refractive index of the ternary mixtures to obtain the experimental compositions of the equilibrium phases. The LS and LSh regions close to the binaries alcohol + salt and water + salt, respectively, were found to be extremely reduced. The LLE region defines an ATPS of interest for separations of biomolecules due to the high water content of equilibrium phases. Tieline length in this biphasic region increases with the alkyl chain length of the alcohol, and with temperature. In these cases, smaller quantities of chemicals would be required to form the ATPS.

The correlation of all data sets in the different regions requires the equations representing equilibrium in each region. Moreover, the total miscibility of the water + alcohol binary subsystem must be imposed as a restriction during the correlation procedure in order to avoid the liquid-liquid splitting of this binary. This is due to the extreme proximity of the ternary tie-lines of the LLE region to the miscible water + alcohol pair. With these considerations, NRTL adequately correlates the whole phase diagram for each ternary system and temperature. The deviations between the experimental and calculated mole fractions for the system with ethanol are lower than 
those with propanol. This is due to the proximity of the LLE region to the miscible water + propanol binary subsystem. NRTL is also able to simultaneously correlate data at all the temperatures using temperature dependent parameters. Deviations are slightly higher than in the case of the individual correlation at each temperature.

The correlation of tie-lines only corresponding to the LLE region in the system with ethanol at $288.15 \mathrm{~K}$ leads to very similar deviations to those obtained in the correlation of all the regions. As in the previous instance, deviations are also higher in the case of propanol. The advantage of this kind of correlation is its facility of computation but the drawback is that parameters are only valid for this region.

The common tangent criterion to minimise the Gibbs energy of mixing of the system has proven to be a very useful method to check consistency of correlation parameters, discarding possible metastable equilibrium solutions.

Typically, the literature of ATPS phase diagrams are restricted to the LLE region as that is the region of practical interest for extraction processes. Indeed, most works just present a limited set of tie-lines that do not cover the whole LLE region. The correlation of such tie-lines may produce a set of parameters that predict erroneous behaviour in other regions of the phase diagram, with dramatic effects on chemical process simulations, such as alcohol/water immiscibility. This work proves that extending the correlation to other regions of the phase diagram does not negatively affect the quality of the correlation, while providing safer parameters for use in process simulation.

\section{Acknowledgment}

The authors are grateful to Xunta de Galicia for support through project ED431B 2017/023 and the Galician Network of Ionic Liquids (ED431D 2017/06) and the CRETUS Strategic Partnership (ED431E 2018/01), co-funded by the European Regional Development Fund.

\section{Supporting Information}

Density and refractive index of binary and ternary mixtures at $298.15 \mathrm{~K}$, physical property calibration curves for compositional analysis, NRTL binary parameters and sectional planes of the $g^{M, L}$ surface in the LLE region. 


\section{References}

(1) Pereira, J. F. B.; Freire, M. G.; Coutinho, J. A. P. Aqueous Two-Phase Systems: Towards Novel and More Disruptive Applications. Fluid Phase Equilib. 2019, 505, 112341.

(2) Zaslavsky, B.Y. Aqueous two-phase partitioning: physical chemistry and bioanalytical applications; CRC Press Marcel Dekker, Inc.: New York, 1995.

(3) Freire, M. G.; Cláudio, A. F. M.; Araújo, J. M. M.; Coutinho, J. A. P.; Marrucho, I. M.; Lopes, J. N. C.; Rebelo, L. P. N. Aqueous Biphasic Systems: A Boost Brought about by Using Ionic Liquids. Chem. Soc. Rev. 2012, 41 (14), 4966.

(4) Freire, M.G. Ionic-liquid-based aqueous biphasic systems: Fundamentals and Applications; Springer-Berlin Heidelberg, 2016.

(5) Grilo, A. L.; Aires-Barros, M. R.; Azevedo, A. M. Partitioning in Aqueous TwoPhase Systems: Fundamentals, Applications and Trends. Sep. Purif. Rev. 2016, 45, 68.

(6) Hann, S. D.; Lee, D.; Stebe, K. J. Tuning Interfacial Complexation in Aqueous Two Phase Systems with Polyelectrolytes and Nanoparticles for Compound All Water Emulsion Bodies (AWE-Somes). Phys. Chem. Chem. Phys. 2017, 19 (35), 23825.

(7) Torres-Acosta, M. A.; Mayolo-Deloisa, K.; González-Valdez, J.; RitoPalomares, M. Aqueous Two-Phase Systems at Large Scale: Challenges and Opportunities. Biotechnol. J. 2019, 14, 1.

(8) Merchuk, J. C.; Andrews, B. A.; Asenjo, J. A. Aqueous Two-Phase Systems for Protein Separation Studies on Phase Inversion. J. Chromatogr. B Biomed. Appl. 1998, $711,285$.

(9) Guan, Y.; Lilley, T. H.; Treffry, T. E. A New Excluded Volume Theory and Its Application to the Coexistence Curves of Aqueous Polymer Two-Phase Systems. Macromolecules 1993, 26, 3971.

(10) Renon, H.; Prausnitz, J. M. Local compositions in thermodynamic excess functions for liquid mixtures. AIChE J. 1968, 14, 135.

(11) Mohammad, S.; Grundl, G.; Müller, R.; Kunz, W.; Sadowski, G.; Held, C. Influence of Electrolytes on Liquid-Liquid Equilibria of Water/1-Butanol and on the Partitioning of 5-Hydroxymethylfurfural in Water/1-Butanol. Fluid Phase Equilib. 2016, 428,102 .

(12) Mohammad, S.; Held, C.; Altuntepe, E.; Köse, T.; Gerlach, T.; Smirnova, I.; Sadowski, G. Salt Influence on MIBK/Water Liquid-Liquid Equilibrium: Measuring and Modeling with EPC-SAFT and COSMO-RS. Fluid Phase Equilib. 2016, 416, 83. 
(13) González-Amado, M.; Rodil, E.; Arce, A.; Soto, A.; Rodríguez, O. Polyethylene Glycol (1500 or 600) - Potassium Tartrate Aqueous Two-Phase Systems. Fluid Phase Equilib. 2018, 470, 120.

(14) Marcilla, A.; Reyes-Labarta, J. A.; Olaya, M. M.; Serrano, M. D. Simultaneous Correlation of Liquid-Liquid, Liquid-Solid, and Liquid-Liquid-Solid Equilibrium Data for Water + Organic Solvent + Salt Ternary Systems: Hydrated Solid Phase Formation. Ind. Eng. Chem. Res. 2008, 47, 2100.

(15) Olaya, M. M.; Marcilla, A.; Serrano, M. D.; Botella, A.; Reyes-Labarta, J. A. Simultaneous Correlation of Liquid-Liquid, Liquid-Solid, and Liquid-Liquid-Solid Equilibrium Data for Water + Organic Solvent + Salt Ternary Systems. Anhydrous Solid Phase. Ind. Eng. Chem. Res. 2007, 46, 7030.

(16) Marcilla, A.; Reyes-Labarta, J. A.; Olaya, M. M. Should We Trust All the Published LLE Correlation Parameters in Phase Equilibria? Necessity of Their Assessment Prior to Publication. Fluid Phase Equilib. 2017, 433, 243.

(17) Marcilla, A.; Reyes-Labarta, J. A.; Serrano, M. D.; Olaya, M. M. GE Models and Algorithms for Condensed Phase Equilibrium Data Regression in Ternary Systems: Limitations and Proposals. Open Thermodyn. J. 2011, 5, 48.

(18) Reyes-Labarta, J. A.; Olaya, M. M.; Velasco, R.; Serrano, M. D.; Marcilla, A. Correlation of the Liquid-Liquid Equilibrium Data for Specific Ternary Systems with One or Two Partially Miscible Binary Subsystems. Fluid Phase Equilib. 2009, 278, 9.

(19) Marcilla, A.; Olaya, M. M.; Serrano, M. D.; Reyes-Labarta, J. A. Aspects to Be Considered for the Development of a Correlation Algorithm for Condensed Phase Equilibrium Data of Ternary Systems. Ind. Eng. Chem. Res. 2010, 49, 10100.

(20) Wang, Y.; Yan, Y.; Hu, S.; Han, J.; Xu, X. Phase Diagrams of Ammonium Sulfate + Ethanol/1-Propanol/2-Propanol + Water Aqueous Two-Phase Systems at 298.15 K and Correlation. J. Chem. Eng. Data 2010, 55, 876.

(21) Tan, Z. J.; Li, F. F.; Xu, X. L. Extraction and Purification of Anthraquinones Derivatives from Aloe Vera L. Using Alcohol/Salt Aqueous Two-Phase System. Bioprocess Biosyst. Eng. 2013, 36, 1105.

(22) Han, J.; Wu, Y; Xiang, Y.; Wang, Y.; Ma, J.; Hu, Y. Liquid-liquid equilibria of hydrophilic alcohol + sodium hydroxide + water systems: Experimental and correlation. Thermochim. Acta 2013, 566, 261. 
(23) Zafarani-Moattar, M. T.; Hosseinpour-Hashemi, V.; Tolouei, S. Liquid-Liquid Equilibrium Data of the Ternary Systems Containing 1-Propanol/2-Propanol + Dipotassium Tartrate/Potassium Sodium Tartrate + Water at $\mathrm{T}=298.15$ K. J. Chem. Eng. Data 2013, 58, 1223.

(24) Prausnitz, J. M.; Lichtenthaler, R. N.; Gomes de Azevedo, E. Molecular Thermodynamics of Fluid-Phase Equilibria; 3rd ed., Prentice Hall PTR, Upper Saddle River, NJ, 1999. 
Table 1. Pure components used in this work.

\begin{tabular}{ccccc}
\hline Name & CAS & Supplier & $\begin{array}{c}\text { Purification } \\
\text { method }\end{array}$ & Purity (wt \%) \\
\hline Distilled water & $7732-18-5$ & $\begin{array}{c}- \\
\text { Panreac } \\
\text { Ethanol (EtOH) }\end{array}$ & $\begin{array}{c}\text { Molecular } \\
\text { sieve } \\
\text { Applichem }\end{array}$ & $\begin{array}{c}\text { Molecular } \\
\text { sieve }\end{array}$ \\
$\begin{array}{c}\text { 1-Propanol (PrOH) } \\
\begin{array}{c}\text { Potassium Tartrate } \\
\text { Hemihydrate }\end{array}\end{array}$ & $61-23-8$ & Riedel-de Haën & 99.8 \\
\hline
\end{tabular}


Table 2. Equilibrium data (mole fraction) for water (1) + ethanol (2) + dipotassium tartrate (3) ternary system at $288.15,298.15$ and $308.15 \mathrm{~K}$ and $0.1 \mathrm{MPa}$.

\begin{tabular}{|c|c|c|c|c|c|c|c|c|c|c|}
\hline$T(\mathbf{K})$ & Region & $x_{1}^{\alpha}$ & $x_{2}^{\alpha}$ & $x_{3}{ }^{\alpha}$ & $x_{1}^{\beta}$ & $x_{2}{ }^{\beta}$ & $x_{3}^{\beta}$ & $x_{1}^{\gamma}$ & $\boldsymbol{x}_{2}^{\gamma}$ & $x_{3}^{\gamma}$ \\
\hline \multirow[t]{11}{*}{288.15} & LL & 0.896 & 0.014 & 0.090 & 0.533 & 0.465 & 0.002 & & & \\
\hline & & 0.902 & 0.030 & 0.068 & 0.670 & 0.327 & 0.003 & & & \\
\hline & & 0.903 & 0.033 & 0.064 & 0.694 & 0.302 & 0.004 & & & \\
\hline & & 0.903 & 0.039 & 0.058 & 0.725 & 0.270 & 0.005 & & & \\
\hline & & 0.899 & 0.048 & 0.053 & 0.758 & 0.235 & 0.007 & & & \\
\hline & & 0.895 & 0.059 & 0.046 & 0.788 & 0.202 & 0.010 & & & \\
\hline & & 0.888 & 0.073 & 0.040 & 0.813 & 0.172 & 0.015 & & & \\
\hline & LLSh & 0.893 & 0.012 & 0.095 & 0.513 & 0.485 & 0.002 & 0.333 & 0.000 & 0.667 \\
\hline & $\mathrm{LSh}_{\mathrm{I}}$ & 0.900 & 0.000 & 0.100 & & & & 0.333 & 0.000 & 0.667 \\
\hline & $\mathrm{LSh}_{\text {II }}$ & 0.001 & 0.998 & 0.001 & & & & 0.333 & 0.000 & 0.667 \\
\hline & LS & 0.000 & 1.000 & 0.000 & & & & 0.000 & 0.000 & 1.000 \\
\hline \multirow[t]{11}{*}{298.15} & LL & 0.898 & 0.015 & 0.087 & 0.529 & 0.469 & 0.002 & & & \\
\hline & & 0.903 & 0.032 & 0.065 & 0.653 & 0.344 & 0.003 & & & \\
\hline & & 0.906 & 0.034 & 0.060 & 0.680 & 0.317 & 0.003 & & & \\
\hline & & 0.904 & 0.041 & 0.055 & 0.709 & 0.286 & 0.005 & & & \\
\hline & & 0.899 & 0.051 & 0.050 & 0.739 & 0.255 & 0.006 & & & \\
\hline & & 0.897 & 0.059 & 0.044 & 0.769 & 0.223 & 0.008 & & & \\
\hline & & 0.889 & 0.071 & 0.040 & 0.789 & 0.199 & 0.012 & & & \\
\hline & LLSh & 0.891 & 0.012 & 0.097 & 0.476 & 0.522 & 0.002 & 0.333 & 0.000 & 0.667 \\
\hline & $\mathrm{LSh}_{\mathrm{I}}$ & 0.898 & 0.000 & 0.102 & & & & 0.333 & 0.000 & 0.667 \\
\hline & $\mathrm{LSh}_{\text {II }}$ & 0.001 & 0.998 & 0.001 & & & & 0.333 & 0.000 & 0.667 \\
\hline & LS & 0.000 & 1.000 & 0.000 & & & & 0.000 & 0.000 & 1.000 \\
\hline \multirow[t]{11}{*}{308.15} & LL & 0.898 & 0.016 & 0.086 & 0.502 & 0.496 & 0.002 & & & \\
\hline & & 0.902 & 0.033 & 0.065 & 0.631 & 0.367 & 0.002 & & & \\
\hline & & 0.904 & 0.038 & 0.058 & 0.662 & 0.334 & 0.004 & & & \\
\hline & & 0.901 & 0.045 & 0.054 & 0.686 & 0.310 & 0.004 & & & \\
\hline & & 0.900 & 0.051 & 0.049 & 0.714 & 0.280 & 0.006 & & & \\
\hline & & 0.894 & 0.062 & 0.044 & 0.741 & 0.251 & 0.008 & & & \\
\hline & & 0.890 & 0.070 & 0.040 & 0.758 & 0.233 & 0.009 & & & \\
\hline & LLSh & 0.889 & 0.009 & 0.102 & 0.438 & 0.560 & 0.002 & 0.333 & 0.000 & 0.667 \\
\hline & $\mathrm{LSh}_{\mathrm{I}}$ & 0.894 & 0.000 & 0.106 & & & & 0.333 & 0.000 & 0.667 \\
\hline & $\mathrm{LSh}_{\text {II }}$ & 0.001 & 0.998 & 0.001 & & & & 0.333 & 0.000 & 0.667 \\
\hline & LS & 0.000 & 1.000 & 0.000 & & & & 0.000 & 0.000 & 1.000 \\
\hline
\end{tabular}


Table 3. Equilibrium data (mole fraction) for water (1) + 1-propanol (2) + dipotassium tartrate (3) ternary system at $288.15,298.15$ and $308.15 \mathrm{~K}$ and $0.1 \mathrm{MPa}$.

\begin{tabular}{|c|c|c|c|c|c|c|c|c|c|c|}
\hline$T(\mathbf{K})$ & Region & $x_{1}^{\alpha}$ & $x_{2}{ }^{\alpha}$ & $x_{3}{ }^{\alpha}$ & $x_{1}^{\beta}$ & $x_{2}{ }^{\beta}$ & $x_{3}{ }^{\beta}$ & $x_{1}^{\gamma}$ & $\boldsymbol{x}_{2}^{\gamma}$ & $\boldsymbol{x}_{3}^{\gamma}$ \\
\hline \multirow[t]{10}{*}{288.15} & LL & 0.916 & 0.000 & 0.084 & 0.349 & 0.648 & 0.003 & & & \\
\hline & & 0,924 & 0,002 & 0,074 & 0.387 & 0.611 & 0.002 & & & \\
\hline & & 0.938 & 0.010 & 0.052 & 0.474 & 0.524 & 0.002 & & & \\
\hline & & 0.948 & 0.014 & 0.038 & 0.569 & 0.430 & 0.001 & & & \\
\hline & & 0.950 & 0.022 & 0.028 & 0.601 & 0.398 & 0.001 & & & \\
\hline & & 0.948 & 0.028 & 0.023 & 0.642 & 0.357 & 0.001 & & & \\
\hline & LLSh & 0.896 & 0.000 & 0.104 & 0.324 & 0.674 & 0.002 & 0.333 & 0.000 & 0.667 \\
\hline & $\mathrm{LSh}_{\mathrm{I}}$ & 0.896 & 0.000 & 0.104 & & & & 0.333 & 0.000 & 0.667 \\
\hline & $\mathrm{LSh}_{\text {II }}$ & 0.001 & 0.998 & 0.001 & & & & 0.333 & 0.000 & 0.667 \\
\hline & LS & 0.000 & 1.000 & 0.000 & & & & 0.000 & 0.000 & 1.000 \\
\hline \multirow[t]{10}{*}{298.15} & LL & 0.903 & 0.001 & 0.096 & 0.309 & 0.689 & 0.002 & & & \\
\hline & & 0.925 & 0.001 & 0.074 & 0.378 & 0.620 & 0.002 & & & \\
\hline & & 0.938 & 0.009 & 0.053 & 0.465 & 0.533 & 0.002 & & & \\
\hline & & 0.947 & 0.013 & 0.040 & 0.517 & 0.481 & 0.002 & & & \\
\hline & & 0.949 & 0.019 & 0.032 & 0.565 & 0.433 & 0.002 & & & \\
\hline & & 0.949 & 0.026 & 0.025 & 0.615 & 0.384 & 0.001 & & & \\
\hline & LLSh & 0.892 & 0.000 & 0.108 & 0.294 & 0.703 & 0.003 & 0.333 & 0.000 & 0.667 \\
\hline & $\mathrm{LSh}_{\mathrm{I}}$ & 0.892 & 0.000 & 0.108 & & & & 0.333 & 0.000 & 0.667 \\
\hline & $\mathrm{LSh}_{\text {II }}$ & 0.001 & 0.998 & 0.001 & & & & 0.333 & 0.000 & 0.667 \\
\hline & LS & 0.000 & 1.000 & 0.000 & & & & 0.000 & 0.000 & 1.000 \\
\hline \multirow[t]{10}{*}{308.15} & LL & 0.911 & 0.000 & 0.089 & 0.341 & 0.657 & 0.002 & & & \\
\hline & & 0.928 & 0.000 & 0.072 & 0.385 & 0.613 & 0.002 & & & \\
\hline & & 0.940 & 0.008 & 0.051 & 0.469 & 0.530 & 0.001 & & & \\
\hline & & 0.948 & 0.013 & 0.039 & 0.520 & 0.479 & 0.001 & & & \\
\hline & & 0.951 & 0.019 & 0.030 & 0.565 & 0.434 & 0.001 & & & \\
\hline & & 0.952 & 0.023 & 0.025 & 0.592 & 0.407 & 0.001 & & & \\
\hline & LLSh & 0.889 & 0.000 & 0.111 & 0.305 & 0.693 & 0.002 & 0.333 & 0.000 & 0.667 \\
\hline & $\mathrm{LSh}_{\mathrm{I}}$ & 0.889 & 0.000 & 0.111 & & & & 0.333 & 0.000 & 0.667 \\
\hline & $\mathrm{LSh}_{\text {II }}$ & 0.001 & 0.998 & 0.001 & & & & 0.333 & 0.000 & 0.667 \\
\hline & LS & 0.000 & 1.000 & 0.000 & & & & 0.000 & 0.000 & 1.000 \\
\hline
\end{tabular}


Table 4. NRTL binary parameters obtained in the correlation of all equilibrium data shown in Table 2 for water (1) + ethanol (2) + dipotassium tartrate (3) ternary system at $288.15,298.15$ and $308.15 \mathrm{~K}$.

\begin{tabular}{cccccccccc}
\hline $\boldsymbol{T}(\mathbf{K})$ & $\boldsymbol{i}$ & $\boldsymbol{j}$ & $\Delta \boldsymbol{g}_{i j}(\mathbf{J} / \mathbf{m o l})$ & $\Delta \boldsymbol{g}_{j \boldsymbol{i}}(\mathbf{J} / \mathbf{m o l})$ & $\alpha_{i j}=\alpha_{j i}$ & $\boldsymbol{g}^{S}$ & $\boldsymbol{g}^{S h}$ & $\boldsymbol{O} . \boldsymbol{F}$. & $\boldsymbol{\sigma}(\boldsymbol{\%})$ \\
\hline 288.15 & 1 & 2 & 5083.09 & -3323.41 & 0.4818 & -1.066 & -6.315 & 0.0033 & 0.63 \\
& 1 & 3 & 16526.4 & -8372.56 & 0.5716 & & & & \\
298.15 & 2 & 3 & 4175.42 & 21578.3 & 0.1045 & & & & \\
& 1 & 2 & 5472.70 & -3293.47 & 0.4155 & -1.020 & -5.794 & 0.0022 & 0.52 \\
& 2 & 3 & 15879.8 & -7674.96 & 0.6713 & & & & \\
308.15 & 1 & 2 & 4218.63 & 22507.9 & 0.1076 & & & & \\
& 1 & 3 & 15069.1 & -7516.44 & 0.6755 & & & & \\
& 2 & 3 & 4325.87 & 23142.7 & 0.1002 & & & & \\
\hline
\end{tabular}


Table 5. NRTL binary parameters obtained in the correlation of all equilibrium data shown in Table 3 for water (1) + 1-propanol (2) + dipotassium tartrate (3) ternary system at $288.15,298.15$ and $308.15 \mathrm{~K}$.

\begin{tabular}{cccccccccc}
\hline $\boldsymbol{T}(\mathbf{K})$ & $\boldsymbol{i}$ & $\boldsymbol{j}$ & $\Delta \boldsymbol{g}_{\boldsymbol{i j}}(\mathrm{J} / \mathbf{m o l})$ & $\Delta \boldsymbol{g}_{\boldsymbol{j i}}(\mathbf{J} / \mathbf{m o l})$ & $\alpha_{i j}=\alpha_{j i}$ & $\boldsymbol{g}^{S}$ & $\boldsymbol{g}^{S \boldsymbol{h}}$ & $\boldsymbol{O . F .}$ & $\boldsymbol{\sigma}(\boldsymbol{\%})$ \\
\hline 288.15 & 1 & 2 & 9019.40 & -11758.0 & 0.7829 & -0.293 & -3.803 & 0.0814 & 3.23 \\
& 1 & 3 & 5094.11 & -13861.4 & 0.9900 & & & & \\
298.15 & 2 & 3 & 11569.8 & 20910.3 & 0.0825 & & & & \\
& 1 & 2 & 7761.42 & -9717.80 & 0.7882 & -2.087 & -8.269 & 0.1080 & 3.72 \\
& 1 & 3 & -15097.7 & -12406.5 & 0.9900 & & & & \\
308.15 & 1 & 3 & 4038.17 & 81858.4 & 0.0549 & & & & \\
& 1 & 2 & 9853.72 & -10453.2 & 0.6713 & -2.002 & -4.740 & 0.1849 & 4.87 \\
& 2 & 3 & 7087.21 & -13949.8 & 0.8383 & & & & \\
\hline
\end{tabular}


Table 6. NRTL binary parameters obtained in the simultaneous correlation of all equilibrium data shown in Table 2 at all the temperatures for water (1) + ethanol (2) + dipotassium tartrate (3) ternary system.

\begin{tabular}{ccccccc}
\hline $\boldsymbol{i}$ & $\boldsymbol{j}$ & $\boldsymbol{a}_{\boldsymbol{i j}}$ & $\boldsymbol{b}_{\boldsymbol{i j}}(\mathbf{K})$ & $\boldsymbol{c}_{\boldsymbol{i j}}$ & $\boldsymbol{d}_{\boldsymbol{i j}}\left(\mathbf{K}^{-\mathbf{1}}\right)$ & $\boldsymbol{\alpha}_{i j}=\alpha_{j i}$ \\
\hline 1 & 2 & -5.5955 & 1033.2 & -0.18986 & 0.016834 & 0.3448 \\
2 & 1 & 0.89529 & -898.99 & 0.92395 & -0.011396 & 0.3448 \\
1 & 3 & 6.3983 & -1389.3 & -10.955 & 0.16271 & 0.008381 \\
3 & 1 & 4.9930 & -1512.4 & 3.0705 & -0.078615 & 0.008381 \\
2 & 3 & -32.006 & 2700.0 & -7.7092 & 0.14639 & 0.01476 \\
3 & 2 & 18.117 & 2973.9 & -1.1774 & 0.42831 & 0.01476 \\
\hline $\boldsymbol{T}(\mathbf{K})$ & $\boldsymbol{g}^{\boldsymbol{S}}$ & $\boldsymbol{g}^{\boldsymbol{S h}}$ & $\boldsymbol{O . F}$. & $\boldsymbol{\sigma}(\boldsymbol{\%})$ & & \\
\hline 288.15 & -13.270 & -11.888 & 0.0025 & 0.54 & & \\
298.15 & -12.905 & -11.282 & 0.0037 & 0.66 & & \\
308.15 & -12.509 & -10.599 & 0.0141 & 1.29 & & \\
\hline
\end{tabular}




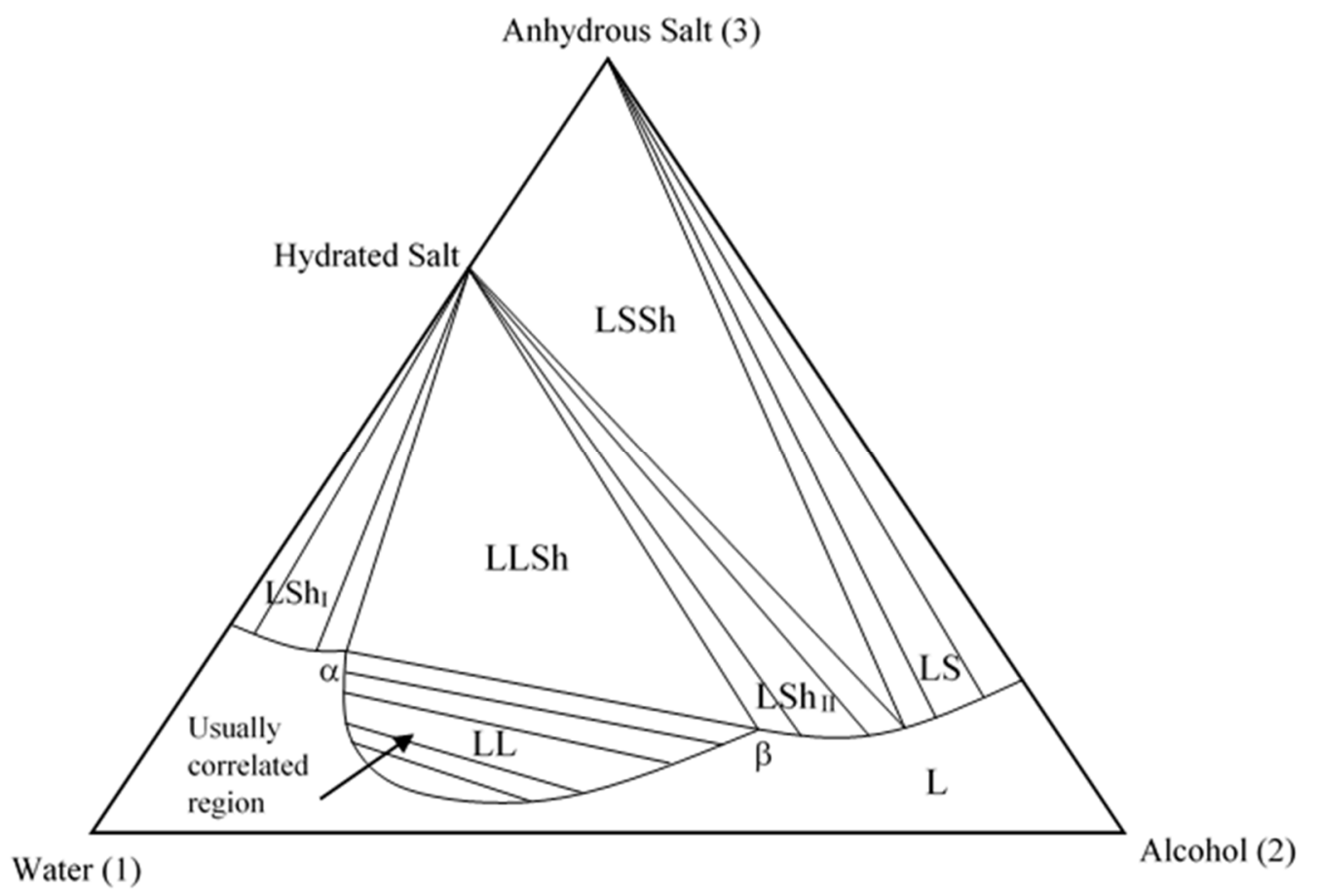

Figure 1. Schematic representation of the equilibrium regions for a water (1) + alcohol (2) + salt (3) ternary system. 


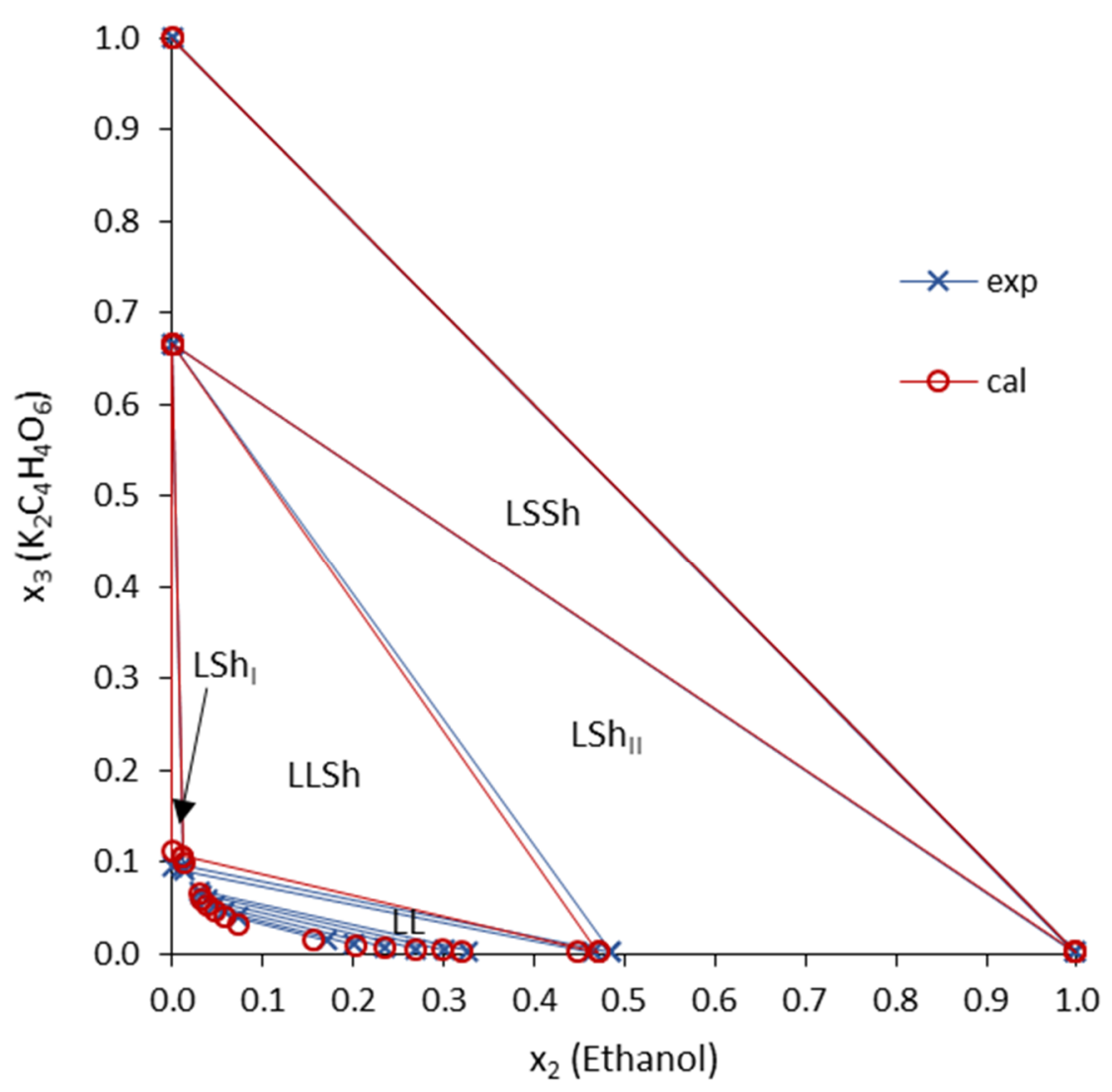

Figure 2. Experimental and calculated equilibrium compositions (mole fractions) for water (1) + ethanol (2) + dipotassium tartrate (3) ternary system at $288.15 \mathrm{~K}$. Calculated data are obtained using NRTL equation with parameters in Table 4. 


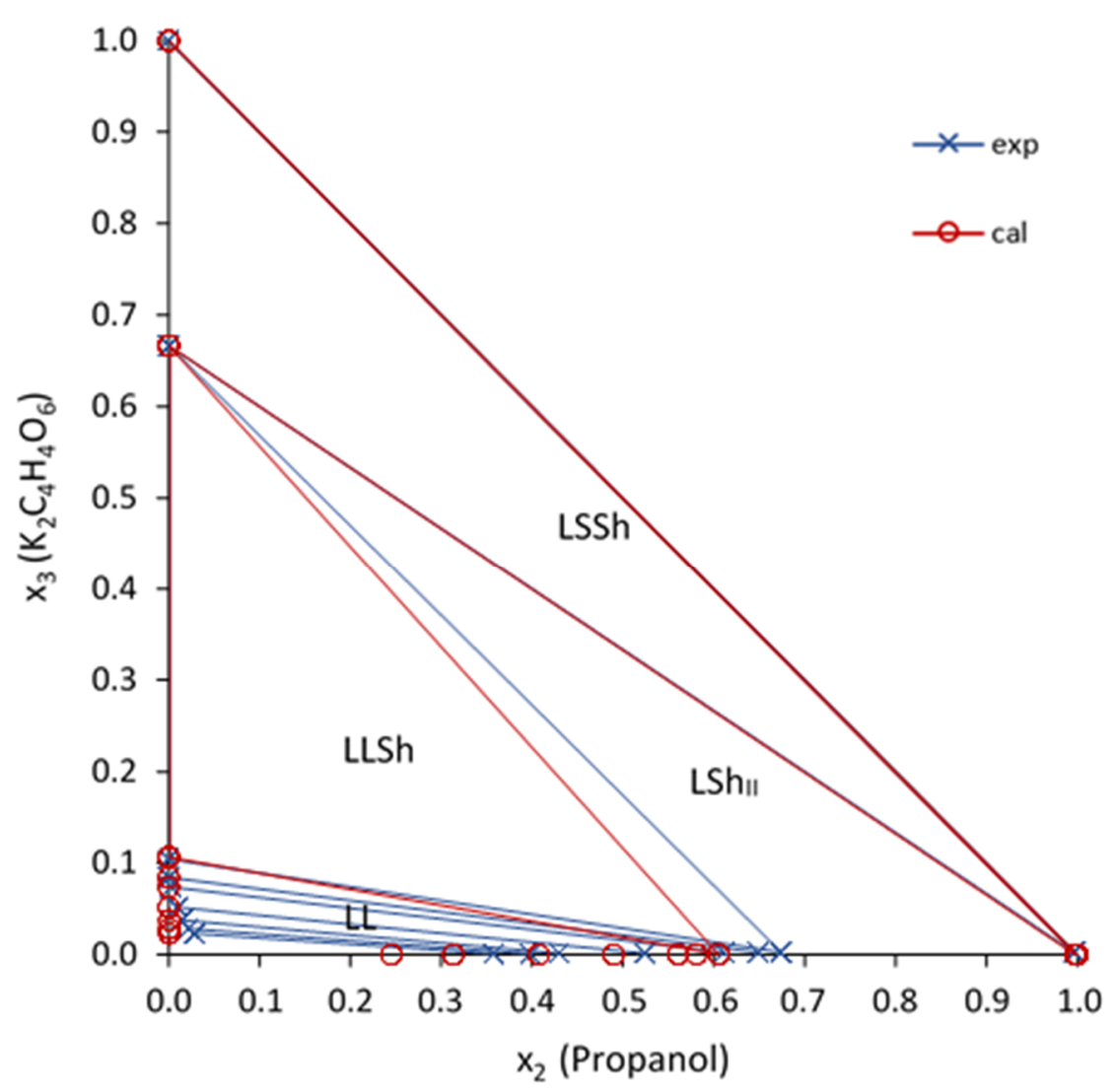

Figure 3. Experimental and calculated equilibrium compositions (mole fractions) for water (1) + propanol (2) + dipotassium tartrate (3) ternary system at $288.15 \mathrm{~K}$. Calculated data are obtained using the NRTL equation with parameters in Table 5. 
a)

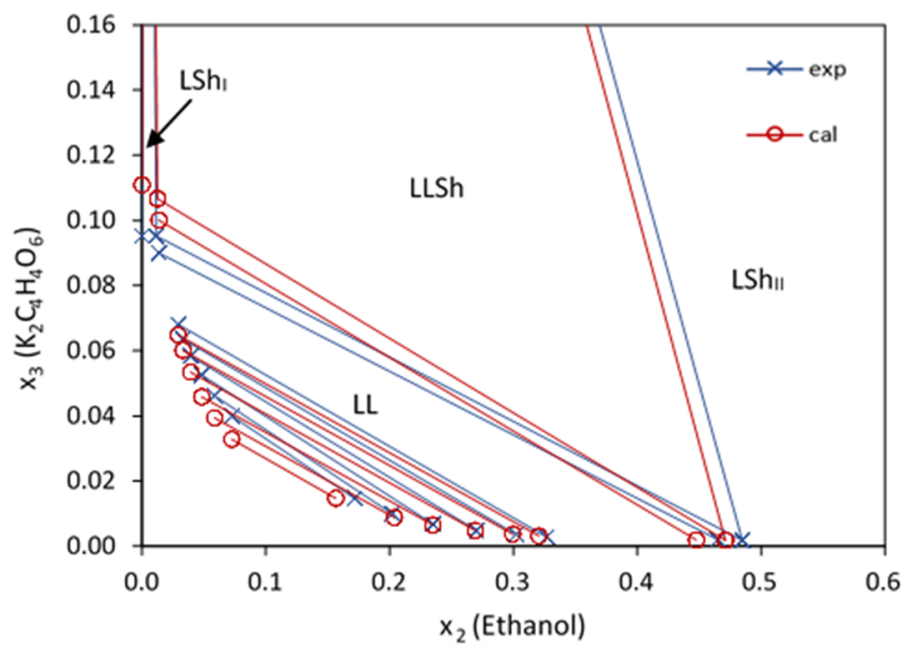

b)

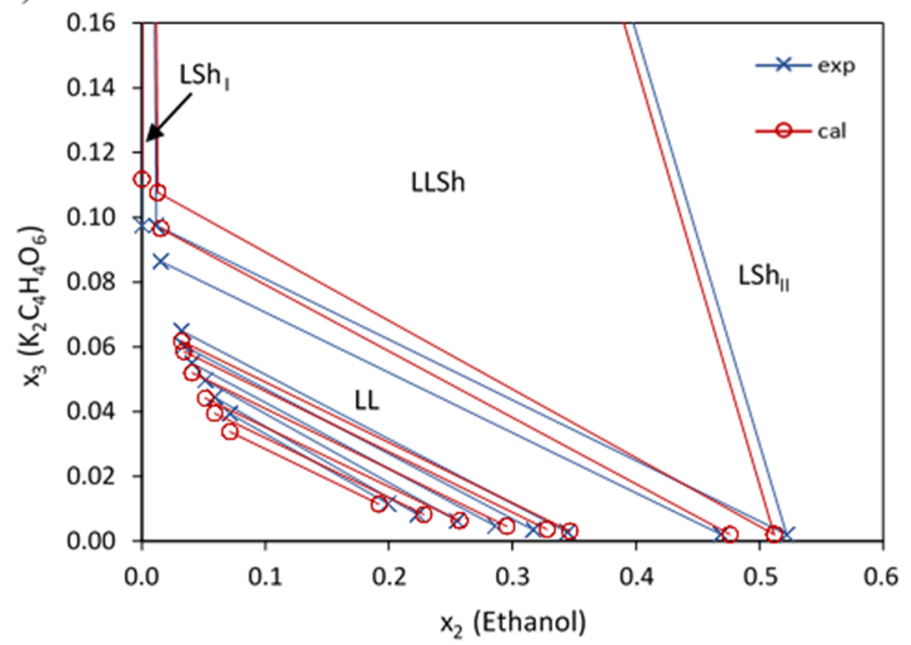

c)

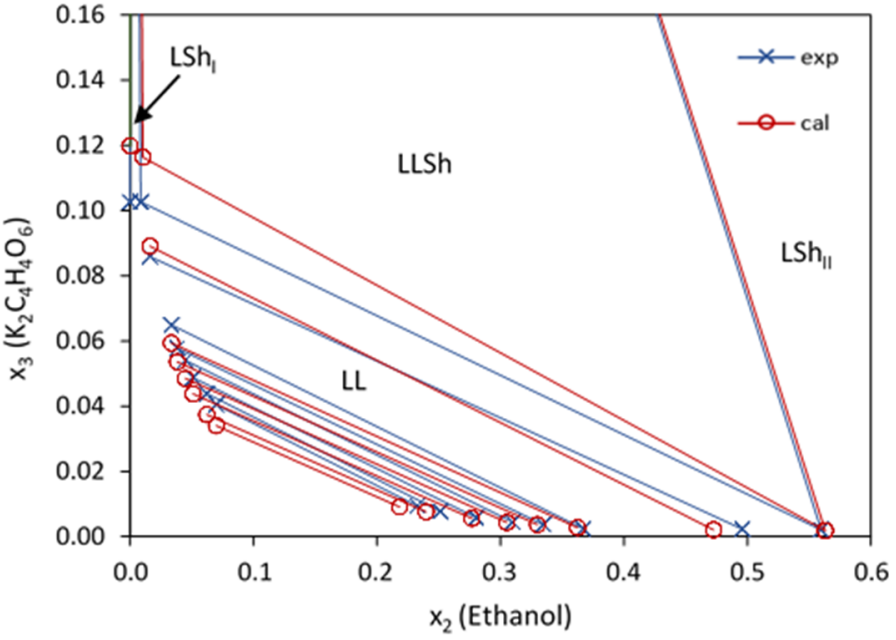

Figure 4. Experimental and calculated LLE tie-lines (mole fractions) for water (1) + ethanol (2) + dipotassium tartrate (3) ternary system at: a) $288.15 \mathrm{~K}$, b) $298.15 \mathrm{~K}$ and c) $308.15 \mathrm{~K}$. Calculated data are obtained using the NRTL equation with parameters in Table 4. 
a)

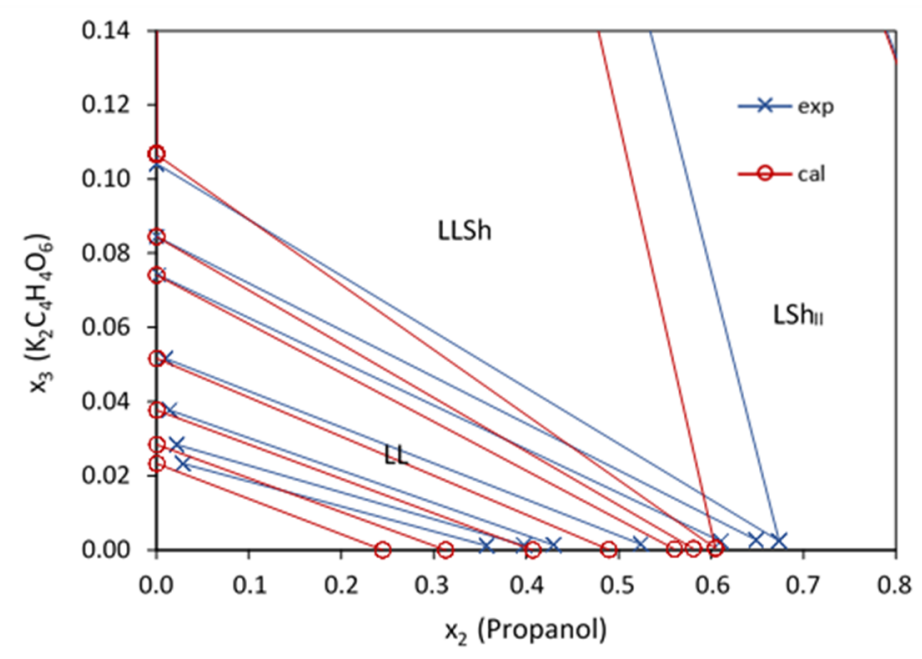

b)
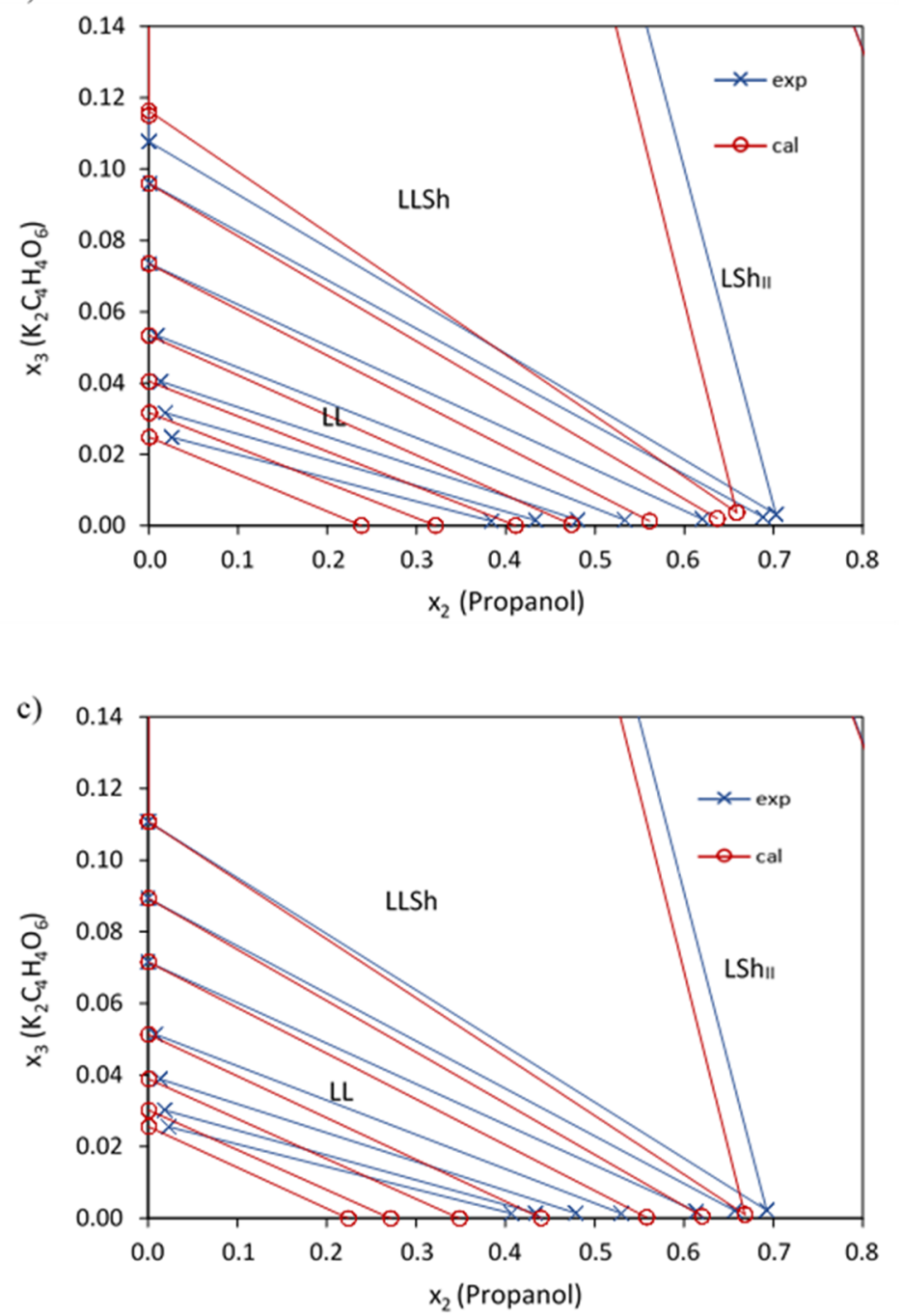

Figure 5. Experimental and calculated LLE tie-lines (mole fractions) for water (1) + propanol (2) + dipotassium tartrate (3) ternary system at: a) $288.15 \mathrm{~K}$, b) $298.15 \mathrm{~K}$ and c) $308.15 \mathrm{~K}$. Calculated data are obtained using the NRTL equation with parameters in Table 5 . 


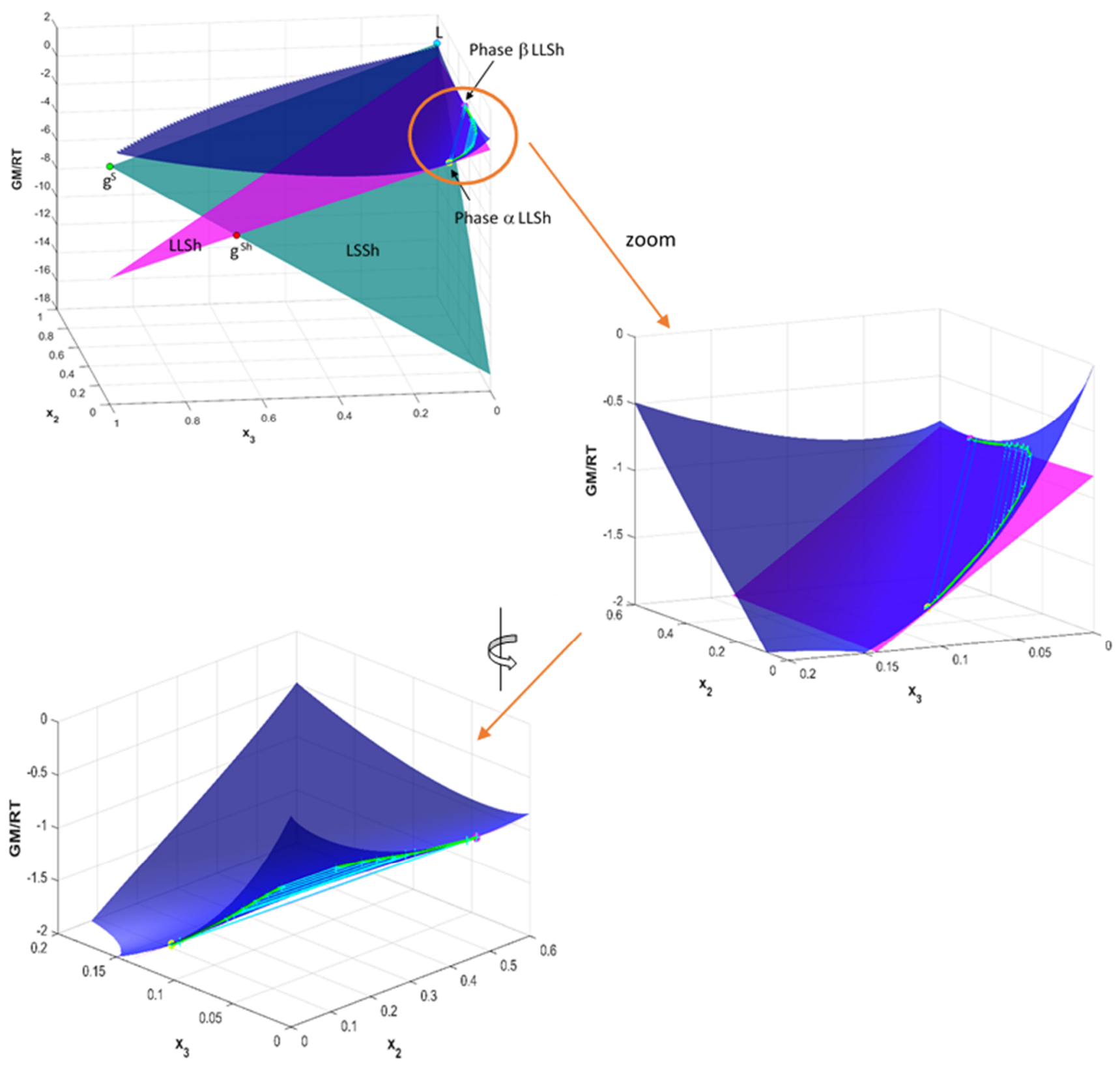

Figure 6. Calculated $g^{M, L}$ surface (NRTL model with parameters in Table 4) and $g^{S}$ and $g^{S h}$ values for water $(1)+$ ethanol $(2)+$ dipotassium tartrate (3) ternary system at $288.15 \mathrm{~K}$. Figure shows the tangent lines and planes in each region: LL, LSh, LLSh, LSSh and LS. Zoom and rotation are shown for a better visualisation of the LL region. 


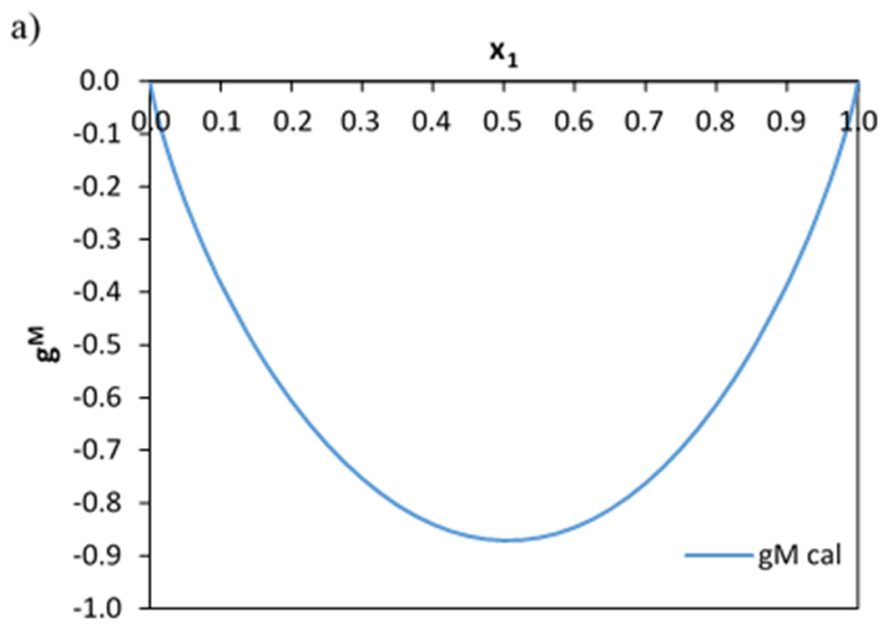

b)

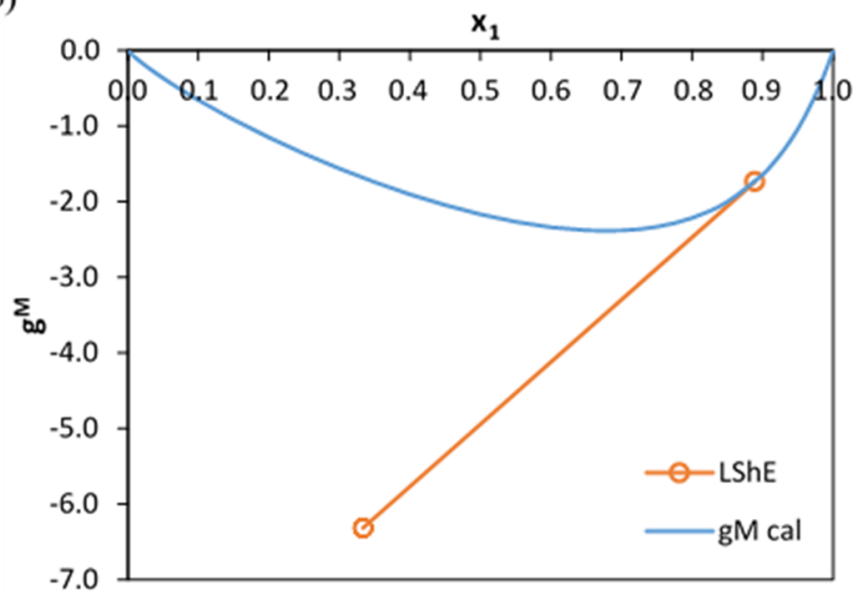

c)

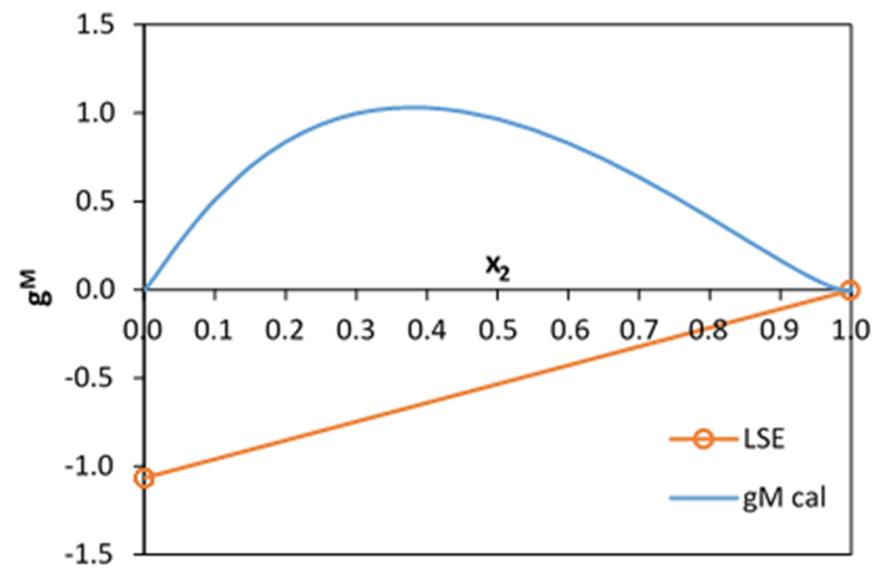

Figure 7. $g^{M}$ values calculated with the NRTL model (parameters in Table 4) for each binary subsystems of water (1) + ethanol (2) + dipotassium tartrate (3) ternary system at 288.15 K. a) Binary (1)-(2); b) Binary (1)-(3), and c) Binary (2)-(3). 


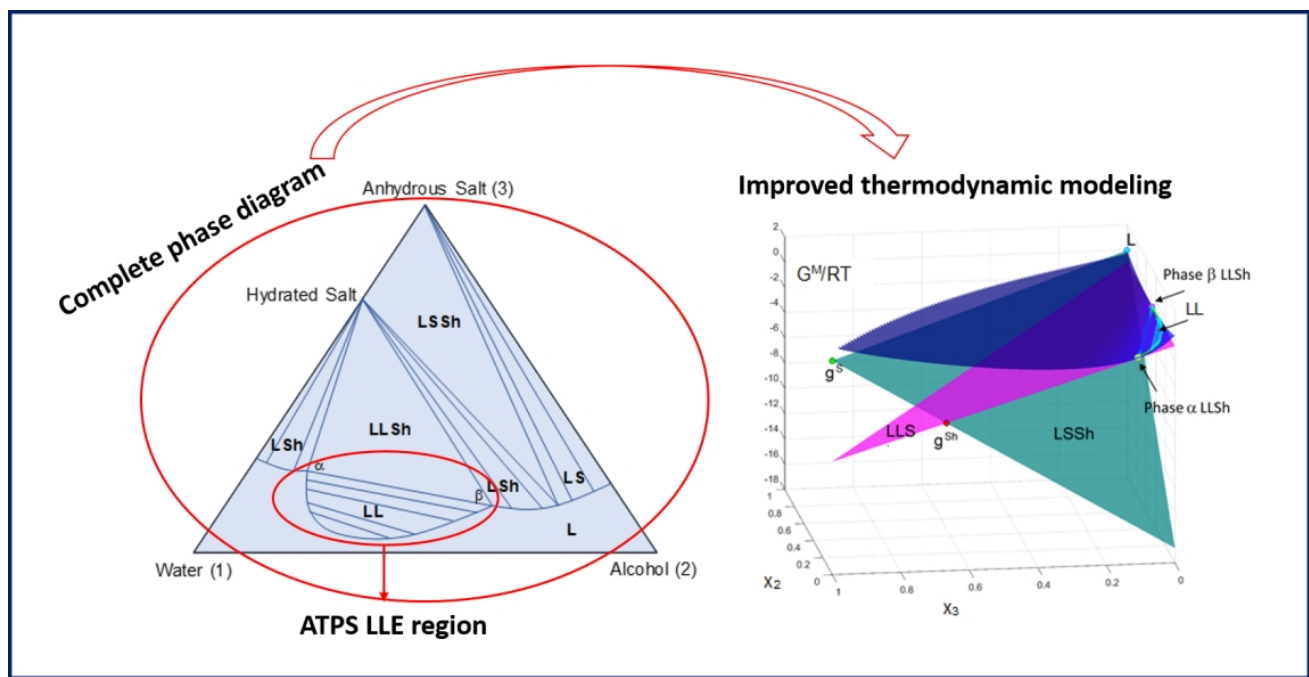

Graphical Abstract

$284 \times 146 \mathrm{~mm}(150 \times 150 \mathrm{DPI})$ 